\title{
humanidades
}

Revista humanidades

Diciembre, $2014 \cdot$ Volumen 4 •ISSN 2215-3934 • pp. 1-27

\section{Nicolás Maquiavelo un amoral con elementos morales: Un acercamiento a su pensamiento desde la ética}

DOI: http://dx.doi.org/10.15517/h.v4i1.16323

Recibido: 15-Julio-2014 / Aceptado: 01-Septiembre-2014

\section{Héctor Eduardo Miranda Fonseca}

Máster, profesor en la Sección de Filosofía y Pensamiento en la Escuela de Estudios Generales de la Universidad de Costa Rica.

Correo electrónico: lic_hector_cr@hotmail.com 


\section{Nicolás Maquiavelo un amoral con elementos morales: Un acercamiento a su pensamiento desde la ética}

\section{Resumen}

El presente trabajo intenta explicar las grandes líneas del pensamiento de Nicolás Maquiavelo, con el fin de establecer su pensamiento amoral y como a través de categorías de análisis intenta explicar su pensamiento alrededor de la política y del reconocimiento del nuevo escenario en Europa, que se comienza a perfilar con la aparición del Estado Moderno y se quiere enmarcar este acercamiento teórico, con el fin de descubrir como en ese pensamiento, en forma larvada se encuentran elementos éticos, que no se descubren en su propio pensamiento, sino en su comportamiento como persona, y por el momento histórico que le toca vivir en Italia.
Palabras clave: Historia, poder, virtud, estado, egoísmo hombre

\section{Machiavelli an amoral with moral elements: An approach to his thought on ethics}

\section{Abstract}

This paper tries to explain the broad outlines of the thought of Nicolás Maquiavelo, in order to establish his amoral thinking and how through categories of analysis tries to explain his thinking around policy and the recognition of the new stage in Europe, is beginning to take shape with the emergence of the modern State, and you want to frame this theoretical approach to the end, discovered at that thought, in overt form are ethical elements, which are not discovered in their own thinking, but in his behavior as a person, and by the historical moment that you live in Italy.
Keywords: History, power, virtue, State, selfishness, man. 
En la historia del pensamiento político, Nicolás Maquiavelo es considerado, en general, el padre de la política. Lo anterior no es para menos, pues realmente él logra circunscribir el objeto de la política, o sea, el problema del poder y cómo utilizarlo. Sin embargo, uno de los elementos que más se ha destacado de este autor es su relación, o mejor dicho, su exclusión de la ética en el campo del quehacer político. Dicha situación se debe a que todos los autores, antes de su aparición en la escena intelectual, hacían un vínculo inevitable entre la ética y la política. Así, Platón, en La República, menciona que deben gobernar los "mejores" o reyes-filósofos, pues son los únicos que pueden realizar un gobierno perfecto, que redundará en hombres en la polis, buenos y perfectos. Incluso, ilustra este vínculo con la ética en su conocido mito del "anillo de la invisibilidad de Gyges" (Platón, La República, p. 38$39)$.

Ahora bien, Aristóteles, aunque muchos lo alaban como un autor que intentará ser más realista, pues en "El Político" desarrolla una visión más vinculada con el momento histórico que le toca vivir, manifiesta la necesidad de un análisis político que vaya de la mano de la ética; para él va a ser suficiente el concepto del "justo medio" y no el "sumo bien" que estructura como pilar fundamental su maestro Platón (Aristóteles, La Política, pp. 134-135). 
En el presente trabajo, entonces, se pretende analizar hasta qué punto Maquiavelo excluye la ética, o si en el fondo lo que realiza es un análisis político que no contempla explícitamente a la ética, pero que es el presupuesto necesario de todo político. A partir de la anterior afirmación, se intenta demostrar que Maquiavelo es un autor sumamente ético, pero esta moralidad debe ser encontrada de una manera distinta a la manifestada por los autores anteriores a él, e incluso a otros que hacen de la política y la ética elementos inseparables.

Maquiavelo es un pensador que debe estudiarse en el contexto de una época conocida en la historia como "El Renacimiento". Primeramente, hay que entender que este período histórico se caracterizó por un redescubrimiento del énfasis teórico de los clásicos griegos, como lo fueron Platón y Aristóteles. Lo anterior no significó la eliminación, de un plumazo, de todo lo construido en la edad media. A todo lo pensado intelectualmente en la Edad Media se le agregan nuevos elementos, que siguen la línea que inaugura Sócrates en Atenas, la cual consiste en una vuelta a enfatizar al hombre como centro del quehacer intelectual.

La Edad Media se había caracterizado por tener un personaje principal de toda especulación intelectual; de él nacían y a él volvían todos los elementos que se descubrían en la realidad. Este personaje fue Dios. La deidad y los 
santos eran los temas fundamentales. La iglesia había logrado un dominio absoluto del pensamiento intelectual y, por ende, su preocupación última: la deidad, eje central de todo pensador. Este pensamiento medieval fue fundamentado principalmente con autores como San Agustín y Santo Tomás, en las obras La Ciudad de Dios con el primero y en relación al segundo con la obra Suma contra los gentiles y el texto Comentarios a los libros de Aristóteles.

Los cambios comienzan cuando cae la idea de los dos poderes, el terrenal y el celestial, los cuales fueron magistralmente expresados por San Agustín de Hipona en su libro La Ciudad de Dios. En donde este autor, explicó que el poder terrenal estaba supeditado al poder celestial, y que siempre que lo celestial tuviera control de lo terrenal, producía el bien y la armonía (San Agustín, 2001, p. 730-820).

Con la aparición del mercantilismo, fase preliminar del capitalismo, el burgués o individuo de la ciudad se convierte en una nueva clase social. Esta clase social comenzará su ascenso al poder acumulando capital, creando una clase bancaria como son los FUGGER de los países bajos, los PERUZZI o los MEDICIS de Florencia (Le Goff, 1982, p. 28-30). 
Según lo expuesto en líneas anteriores, se puede concluir que luego de la crítica a la Edad Media y el cambio económico y político que se comienza a gestar, surgen nuevas estructuras políticas y, por supuesto, el advenimiento del Estado Nacional. Este advenimiento no acontece por obra y gracia de Dios, sino porque hubo guerras para quebrantar el poder de los Papas, pues; desde la época de San Agustín y su tesis de la superioridad del poder espiritual sobre el poder terrenal, los Papas dominaban la escena política. Sin embargo, estos comienzan a sufrir derrotas frente a la jerarquía civil. Así, el Papa Gregorio VII, sufre una derrota con Enrique de Alemania; El Papa Inocencio III con Federico II Barbarroja; El Papa Juan XXII con Luis de Baviera; y el Papa Bonifacio VIII con Felipe El Hermoso (Ullmann, 1965).

Aparejado a lo anterior, comienza una lucha en el campo del derecho, es así como los canonistas, o seguidores del Derecho Canónico, van a tener que enfrentarse a pensadores que comienzan a usar el Derecho Romano y la Política de Aristóteles en sus análisis. Cabe destacar que en esta lucha ideológica, son los Grecorromanos los que llevarán la mejor parte.

Esta época también tiene, como un elemento que precipita los nuevos tiempos, la ampliación de los horizontes geográficos: El descubrimiento de América por Cristóbal Colón, así como los viajes a África, Oceanía y Asia. El encuentro con distintas culturas y el planteamiento de todo un nuevo mundo 
de ideas y costumbres, sin duda, solidifica los cambios que comienzan a realizarse en Europa. Por último, en la época que le toca vivir a Maquiavelo hay una transformación profunda en la Ciencia: aparecen los ilustres Copérnico y Galileo, quienes no solamente nos darán una nueva visión de los astros, sino que, al igual que en geografía hay nuevas tierras, en la astronomía hay nuevos astros.

A partir de lo supra mencionado, es importante destacar que en el Renacimiento hay dos elementos importantes y necesariamente observables: la recuperación de la Cultura Antigua y el nacimiento del humanismo (Burke, 2000).

Para lograr encontrar a Maquiavelo, se debe husmear en esta nueva época llamada Renacimiento, pues solo así se podrá ver, en toda su magnitud, a este pensador, entenderlo y comprobar si es o no un político sin ética.

Es cierto que el objeto de la presente investigación es dilucidar si Maquiavelo es o no un político ético, sin embargo, es necesario, antes de realizar esta labor, fundamentar su pensamiento y entender por qué se habla de él como un autor que excluye la ética. Además, apreciarlo según los estudiosos como el padre de la Ciencia Política. 
Primeramente, Maquiavelo adquiere una relevancia intelectual fundamental por dos obras: El Príncipe (1513) y Los Discursos sobre la primera década de Tito Livio (1531). En el primer escrito intenta explicar cómo actúan los príncipes y cuáles son las leyes de su proceder. En el segundo escrito se preocupa por el gobierno de las repúblicas y cuál es la forma de gobernarlas. Pero, ¿quién fue este hombre y por qué logra escribir estas obras?

Maquiavelo nació en Florencia, procedente de una familia noble Güelfa. Por la posición social, recibe la educación que estaba acorde con esta. En el año de 1498 es nombrado jefe de la segunda cancillería de la República, puesto en que se desempeñará por catorce años. Este régimen será iniciado por Pedro Soderini y Carlos VII, después de la caída de Pedro de Médicis, hijo de Lorenzo El Magnífico. Su cargo le permitió conocer todas las sedes importantes de Italia y de Europa en general; incluso conoció en estos recorridos al hombre más admirado por él: César Borgia, Duque de Valentinois, Roma, en 1503.

Esta vida diplomática le permitió a Maquiavelo, acumular bastantes experiencias y observaciones de la vida política europea de su tiempo. Observó asesinatos, intrigas, el uso de la fuerza y la multitud de artimañas muy comunes entre los políticos en aquella época. En 1513, después de la Batalla de Rávena, es despedido por sospechas de simpatizar con la República, es encarcelado y confinado en la Villa de San Casiano. En esa época se dedicará a leer a Platón, Aristóteles, Polibio, Tácito y Tito Libio,

\section{Su}

pensamiento $\mathbf{y}$ breve biografía 
además, compone sus propias obras. En 1520 retorna a la vida pública, cuando se le encarga, por parte de los Médicis, componer la historia de Florencia. En 1527 fue derribado el gobierno de los Médicis y proclamada la República, por lo que se le despidió y poco después, el 21 de Junio de 1527, murió (Forte, 2011).

Maquiavelo, según algunos pensadores, es un teórico que crea lo que ellos denominan el oportunismo político. Fundamentan esencialmente su aseveración en la doctrina que aparece en el libro El Príncipe. Sin embargo, es importante destacar que Maquiavelo es un humanista y, aunque carece de un sistema filosófico bien estructurado, plantea ideas que revolucionan el quehacer político. Unos autores manifiestan que Maquiavelo es el personaje clásico del mal camino en el pensamiento político. Otros enfatizan en que es el autor preferido de los diplomáticos, incluso, que es el único pensador serio en política.

Maquiavelo nos manifiesta en su obra las negociaciones, valoraciones; así como las habilidades en el juego político. Es en el fondo un individualista, pues no maneja en ningún momento la idea de los grupos sociales, ni tampoco la tesis de que el príncipe no sería tal si no tuviera una clase social a su alrededor que lo sostuviera. Fundamentalmente, considera que es el quehacer individual, la astucia y habilidades de ciertos individuos, lo que les permite ascender en el poder. Tal vez es aventurado decir lo anterior, pues 
cabría la hipótesis de que si es un asunto individual, por qué Maquiavelo, siendo tan docto, no intentó por sus propios medios alcanzar el poder. Realmente es una pregunta que en muchas ocasiones surge cuando se piensa en este autor. Sin embargo, no se encuentra asidero a una manifestación de manejo social en el pensamiento de Nicolás, con excepción del análisis que hace sobre la institución del ejército, donde manifiesta que sí es importante manejar este grupo y tenerlo con ciertas condiciones, pues de no ser así peligraría la estabilidad del poder por parte del príncipe.

Y de los fundamentos de todos los Estados, tanto nuevos como antiguos o mixtos, los principales son las buenas leyes y las buenas armas. Y puesto que no puede haber buenas leyes donde no hay buenas armas, y donde hay buenas armas, las leyes son por cierto buenas, omitiré aquí hablar de las leyes para hacerlo sólo de las armas (Maquiavelo, 2011, p. $40)$.

Otro elemento por el cual es alabado Maquiavelo, es su visión realista de la política, pues no piensa en estados ideales como los de Platón, que siempre están dentro del eidòs y vinculados a una idea del bien, que hace que en los estados reales no se encuentre la perfección. Maquiavelo, como ya se dijo, conoció cómo funcionaban los reinos y las actuaciones reales de los príncipes, por lo cual, este autor se sitúa y ve lo real. Es sobre los reinos que 
tiene ante sí, sobre los cuales intenta aplicar sus conocimientos políticos, y es de estos que obtiene sus conocimientos. En este sentido, Maquiavelo es un empirista, y un objetivista, pues usa sus sentidos de observación empírica para crearse una visión de la política, de los Estados o Principados y de las Repúblicas. Asimismo, no imprime una explicación desde el sujeto de los acontecimientos políticos, sino que son los datos sensibles de cómo actúan los príncipes los que dan sentido a la actuación política.

Pues, muchos son los que han imaginado repúblicas y principados que nadie ha visto ni conocido jamás realmente, y está tan lejos el cómo se vive del cómo se debería vivir, que quien renuncia a lo que se hace en aras de lo que debería hacer, aprende más bien su ruina que su conservación; y es que un hombre que quiera hacer en todo profesión de lo bueno, acabará hundiéndose entre tantos que no lo son (Maquiavelo, 2011, p. 51).

La idea del tiempo es interesante en este autor, pues en el fondo, Maquiavelo continúa una visión del tiempo cíclica, igual a la que predominaba en la época griega, y no se ve impregnado por la idea de progreso y linealidad que da el cristianismo, pues en este pensamiento hay un principio en la Biblia, en donde la historia comienza en el libro de Génesis y tiene un final en el libro de Apocalipsis. La idea de un tiempo cíclico y no lineal es una característica de su pensamiento. Esto explica cómo siguen teniendo importancia los acontecimientos pasados, no como elementos para entender el presente, sino por ellos mismos, pues aún hoy pueden repetirse, excepto por los protagonistas, que 
podrían ser diferentes; por ello en sus libros El príncipe, Discurso sobre la primera década de Tito Libio e incluso Sobre el arte de la guerra, están plagados de ejemplos históricos. En este sentido, la historia adquiere una importancia capital, siendo esta en el fondo una forma de adquirir conocimiento, para aprender a gobernar. La historia, entonces, es central para un político, el que no la conozca y no se esfuerce en leer pierde la oportunidad de ser político, pues es la ciencia del arte de la política.

Respecto a lo de ejercitar la mente, debe el príncipe leer historia, poniendo atención a las acciones de los hombres eminentes, viendo cómo se condujeron en las guerras, examinando las causas de sus victorias y derrotas, a fin de evitar éstas e imitar aquellas (Maquiavelo, 2011, p. 49).

Pareciera, entonces, que los grupos sociales no son la causa directa del poder del príncipe, según este autor, pues, es la habilidad individual, el conocimiento e inteligencia de unos individuos, lo que los capacita para ser gobernantes. Este pensamiento, lleva a un nuevo concepto de virtud, que en ocasiones cuando se lee a Maquiavelo, puede inducir a error, pues esta palabra siempre se liga a conceptos como el deber o el bien. Sin embargo, en el pensamiento de este autor, el hombre virtuoso no es el bueno o el que se preocupa por el deber ser, sino aquel que busca obtener el poder y mantenerlo. 
Sé que todo el mundo reconocerá que sería cosa harto laudable que un príncipe reuniese de entre las cualidades citadas las que son tenidas por buenas; pero, puesto que no se pueden tener ni observar enteramente, dado que las condiciones humanas lo impiden, necesita aquél ser tan prudente como para evitar incurrir en los vicios que lo privarían del Estado, y preservarse de los que no se lo quiten mientras ello sea posible; más cuando no lo sea, cabe actuar con menor comedimiento. Y no le preocupe entonces la fama que da el practicar los vicios sin los que la salvaguardia del Estado es imposible, pues si se considera todo debidamente, se hallara algo que parecerá virtud, pero que al seguirlo provocará su ruina, y algo que parecerá vicio, pero que al seguirlo le procurará seguridad y bienestar (Maquiavelo, 2011, p. 52).

El individuo político en este autor, tiene tres ejes sobre los cuales debe manejar su acción. Lo anterior lleva a entender la visión del mundo político de Maquiavelo, quien establece estos tres ejes como leyes, para explicar el entramado político. 
El primero se basa en la concepción de hombre que el autor expresa. El hombre, dice Maquiavelo en El Príncipe, es siempre movido por las mismas pasiones y deseos, no cambia a través del tiempo, tiene una esencia que no doblega el tiempo, por lo cual no hay una construcción de humanidad o un proceso de humanización.

Según demuestran cuantos escritores se han ocupado de la vida civil y prueba la historia con multitud de ejemplos, quien funda un Estado y le da leyes debe suponer a todos los hombres malos y dispuestos a emplear su malignidad natural siempre que la ocasión lo permita (Maquiavelo, 2011, p. 265).

El segundo corresponde a la necesidad del político de conocer la historia que, como ya se dijo, es la maestra de política.

Más para ordenar las repúblicas, mantener los Estados, gobernar los reinos, organizar los ejércitos, administrar la guerra, practicar la justicia, engrandecer el Imperio, no se encuentran ni soberanos, ni repúblicas, ni capitanes ni ciudadanos que acudan a ejemplos de la Antigüedad; lo que en mi opinión procede, no tanto de la debilidad producida por los vicios de nuestra actual religión ni de los males que el ocio orgulloso ha ocasionado a muchas naciones y ciudades cristianas, como de no tener perfecto conocimiento de la historia o de no comprender, al leerla, su verdadero sentido ni el espíritu de sus enseñanzas (Maquiavelo, 2011, p. 250) 
El tercero es que el actuar político siempre tiene el azar o suerte como uno de los elementos que lo conforman. El concepto de suerte en este autor comprende tanto el azar como la fuerza mayor e incluso las fuerzas de la naturaleza. El plantear que el hombre es movido siempre por las mismas pasiones y deseos, como ya se dijo, no es solamente una frase retórica por parte de Maquiavelo, sino que en esta frase se encuentra toda su antropología condensada. En este sentido, sigue a los griegos, que dejan de pensar en la naturaleza y entronizan en su pensamiento al hombre. Así pues, Maquiavelo plantea una visión del hombre como invariable, no hay construcción, en cambio, la naturaleza humana es inmutable. En este sentido, manifiesta una herencia que proviene indudablemente de la Edad Media.

Los autores medievales vinculados al pensamiento cristiano mencionaron, como premisa fundamental, que el hombre era imagen de Dios, lo cual plantea "de facto", la imposibilidad de cambio, pues la deidad impregnó al hombre y solidificó su humanidad. Es un pensamiento esencialista, no hay nada que manifieste el hombre que ya no estuviera en él con anterioridad. Maquiavelo no solo expone que el hombre no cambia en el tiempo, sino que también dice que es movido por los mismos deseos y pasiones. Sin embargo, cuando se intenta descubrir qué significan para el autor estas pasiones, se observa un elemento más de su antropología: además de ser una humanidad incambiable, es manifiestamente egoísta. 
El motor de todo el actuar del ser humano es el bienestar personal, no posee una idea del "buen salvaje de Rousseau" ni nada que se le parezca. (Rousseau, 1996, p. 49) A partir de esta premisa, es que el actuar del príncipe con sus congéneres adquiere significado, pues este debe actuar siempre pensando en el egoísmo natural del hombre. En cualquier momento lo pueden traicionar, no hay lealtad, en nadie se puede confiar. El príncipe debe usar su poder para lograr el mayor beneficio personal. El pueblo o los súbditos no son los que reciben el bien de sus gobernantes, sino todo lo contrario, es el rey el que debe beneficiarse y sacar provecho de sus súbditos. Dentro de este contexto también adquiere sentido la frase que ha tenido tanto impacto en muchos autores: "Es mejor ser temido que amado" (Maquiavelo, 2011, p. 56). Sin embargo, en un contexto de un hombre egoísta y malo, tal frase resulta comprensible. En síntesis esta maldad natural del ser humano hace comprensibles muchas de las frases oportunistas del príncipe.

La gran diferencia con la imagen de Dios es la maldad innata del hombre, que no necesariamente es tan extraña a la Edad Media, pues el pecado, ya lo decía San Agustín, afectó toda la imagen del hombre y la descompuso de su imagen perfecta original. Lo anterior, unido a lo dicho de que Maquiavelo, plantea una historia cíclica, herencia de los griegos, hace que la historia sea fundamental, pues si el hombre es el mismo, va a realizar en la historia muchas acciones similares a las ya hechas por otros hombres. Así, surge en el 
fondo de la concepción de hombre, una historia circular; pues tiene que ver con la idea de que un buen político debe conocer la historia, luego, esta le permitirá al príncipe conocer las virtudes y errores de sus antecesores. Lo anterior solo es posible si el hombre es inmutable, entonces, la historia, por tener un protagonista inmutable, tenderá a repetirse, con lo cual un individuo hábil y estudioso podrá sacar provecho de sus conocimientos, evitando caer en errores del pasado e imitando los aciertos. Por eso es que la idea de la historia como un eterno retorno es fundamental en su pensamiento, pues se deduce de la premisa antes dicha, un hombre inmutable.

Si un político no entiende que se debe buscar el propio bien, sin importar la solidaridad y la piedad natural a su congénere, entonces, no podrá actuar correctamente en la política. A partir de lo anterior, se plantea la hipótesis de todo actuar político según Maquiavelo. Todo político debe tener como premisa "Obtener el poder y mantenerlo" (Maquiavelo, 2011, p. 81-82). A partir de esta ley de la Ciencia Política, el autor deriva toda la actuación política. Asimismo, aparejada a esta tesis, Maquiavelo manifiesta que se necesitan dos cualidades en el político: la inteligencia y la suerte. En la fortuna aparecen, en ese sentido, un elemento positivo y otro negativo, en los cuales por causas foráneas al individuo, este obtiene o pierde el poder. 
El caso de Alejandro Magno es aleccionador, pues, siendo tan hábil como político, al enfermar y morir, la fortuna le fue adversa, con lo cual pierde el poder (Maquiavelo, 2011, p. 14-15).

Luego de tener claros los postulados teóricos de la política en Maquiavelo, se debe entrar en la explicación de los posibles elementos éticos en este autor. Cabe aclarar que en el presente ensayo se pretende ser innovador en el análisis, aunque algunos autores han trabajado en el mismo camino. Ladeducción que plantean no tiene una relación directa con la ética. Tal es el caso del artículo de la Doctora Giglioli, en la Revista de Filosofía de la Universidad de Costa Rica, en la cual arriba a la idea de Maquiavelo como un pensador que busca un gobierno popular (Giglioli, 1990, p. 42).

Es importante, además, entender que Maquiavelo, siendo un autor renacentista, vuelve a la idea de tiempo circular que era la idea dominante en la Edad Media y en la Grecia Antigua. Esta idea le permite, como se dijo, unida a otros elementos plantear su pensamiento. 
Las categorías de espacio y tiempo en un autor siempre son poco explicadas por ellos mismos, son presupuestos que están en la base de sus planteamientos teóricos. Maquiavelo no es la excepción. En virtud de lo anterior, la historia como fenómeno humano es cíclico, lo cual implica que su idea del tiempo es al igual que los griegos: circular.

Esto posiblemente lo dedujera de sus estudios de la historia política de la antigüedad, que aunque era meramente descriptiva, logra darle los suficientes elementos teóricos para su propia elaboración.

Aunado a lo anterior, es importante tener claro que Nicolás Maquiavelo no es un pensador que "rompe" en forma total con todas las teorías anteriores a su tiempo. El que además se le considere renacentista es realmente por desligar a la política de la religión, cosa que se parece mucho a lo hecho por los griegos, cuando se separan de la religión y el mito e intentan explicar el mundo con la sola razón y las distintas capacidades humanas.

En el caso de El Príncipe, Maquiavelo no busca explicaciones religiosas, sino que mediante la observación empírica, así como el uso de todos los conocimientos de los historiadores antiguos leídos, estructura una idea de hombre. La antropología, como se dijo anteriormente, es esencialista. Sin embargo, el esencialismo unido a la idea de tiempo circular va a fortalecer todo su andamiaje teórico que va a crear la idea de un hombre "egoísta". 
Nótese, además, que en este punto del hombre es totalmente agustiniano. Ya el obispo de Hipona había esgrimido la idea de que el pecado original había alterado totalmente la imagen de Dios, por lo cual NO HABIA NADA BUENO EN EL HOMBRE, y este necesitaba la redención, idea que por supuesto Lutero, padre de la Reforma Protestante, va a tomar muy en serio.

Como tesis fundamental de este artículo, se sostiene que Maquiavelo es en el fondo un hombre ético. Sin embargo, su ética no se manifiesta como la vemos en Platón, Aristóteles y otros. Se intenta demostrar que sí hay elementos que confirman la validez de esta afirmación o hipótesis. Primeramente, se plantean tres tesis que demuestran la eticidad de este autor y, luego, se tratará de sustentarlas con argumentos lógicos que se deducen no explícitamente de la obra del autor, sino a través de lo implícito en él.

La circularidad del tiempo, así como la realidad de que los distintos imperios habían conquistado siempre a otros pueblos usando los mismo mecanismos, le demuestran a Maquiavelo que su Italia querida, cuna del Imperio Romano, pilar de la cultura y el humanismo, poseía una fragilidad congénita que de no ser corregida le podría acarrear su desaparición como nación y como legataria de toda una ideología y patrimonio que él consideraba necesario preservar para la humanidad. Lo anterior lo demuestra Maquiavelo cuando narra las dos difíciles circunstancias que atraviesa Italia, tanto con el rey de Francia como con el de España, y reconoce cómo sin la fortuna o azar de parte de Italia, en su país se hubiera llegado a hablar español o francés. De lo anterior se deduce 
implícitamente que Maquiavelo era un nacionalista y que lo que realmente quería era salvaguardar el legado románico básico para todo Occidente. Si esto no fuera así, por qué pensar en darle El Príncipe a Lorenzo El Magnífico.

Al fin y al cabo a un estudioso de la política no debía afectarle que Italia pereciera, pues, el poder debía acumularse y ese era el fin del poder, lograr obtener más poder y saberlo mantener. Si esta es su definición de virtud, aparentemente en forma explícita no quiere que Francia o España se agranden al máximo, lo cual desde su perspectiva de que el príncipe busca maximizar su poder, no puede tener un elemento nacional. Como se observa, Maquiavelo le imprime al concepto de virtud clásico, un nuevo derrotero, que desemboca o bien en una proyección o bien en el deseo de que deben producir la capacidad. No obstante, lo que destaca es la distinción tradicional individual de aprovechar el momento hacia una virtud diferenciada que en el fondo da múltiples elementos de la contingencia, y que no son los esbozados anteriormente, pues la ética del buen gobierno era la virtud, en este autor es esencialmente obtener y mantener el poder, una virtud que se viste de política.

Así las cosas, se observa cómo la igualdad en deseos y egoísmos, universaliza y coacciona la realidad, abarca tanto al individuo como a la multitud, creando un discurso diferente, que se refiere al obrar del príncipe, y, como ya se dijo, trastorna y modifica la comprensión clásica de aquellas virtudes que debe poseer a todos los legitimados en el ejercicio del gobierno. 
De lo dicho en los párrafos anteriores, solo se puede mencionar que a Maquiavelo le surge el nacionalismo porque tiene un amor por su pueblo y por su herencia étnica y cultural, que, por supuesto, lleva a postulados netamente éticos. Pues el amor y la búsqueda de la supervivencia de su nación no se pueden entender desde su teoría, sino desde su ética larvada. Que el bien en su pensamiento sea aumentar el poder, pero que este aumento recayera en Lorenzo de Medici, es incomprensible desde su teoría. Solamente se entiende con una premisa fuera de esta, en donde por motivos distintos se planteara este actuar que no surge de su pensamiento. Se cree que es producto de una opción ética personal, en la cual el amor a la familia Medici es la causa y no una razón que se deduzca de sus escritos, por lo cual se entiende que lleva claramente a un Maquiavelo ético, que quiere el bien de su etnia y de su pueblo, totalmente enraizado en la moral y no en su postura teórica.

Otro elemento que llama la atención y que apunta directamente a su ética implícita es que este autor, a pesar de todo, quiere para su pueblo los beneficios que ha observado en los estados nacionales de Francia y España. El eliminar los feudos y los distintos impuestos de aduanas, el aumentar la población y su control, lograron en ambos países una mayor riqueza, que se manifiesta en mayores ejércitos y en mayores posibilidades para sus habitantes, en cuanto a confort y logros en todos los ámbitos de la vida. Incluso aprovecharse de los pueblos más débiles. 
La pregunta es: ¿Si Maquiavelo es un verdadero científico de la política como algunos sostienen, por qué no le entrega sus consejos a príncipes extranjeros, que ya han logrado consolidar estados nacionales? La respuesta indirecta que, a mi parecer, se deduce es que su nacionalismo y su ética sustentada en un gran amor a su pueblo deciden que su libro sea dedicado y entregado a Lorenzo El Magnífico y no a otro. Algunos, a lo anterior, dirán que fue para recuperar su puesto diplomático, pero hay elementos que no concuerdan, pues si él conocía tanto la historia pudo haber pensado, a partir de su concepción de tiempo, que él mismo podría llevar a cabo la unificación de Italia. Sin embargo, intuitivamente Maquiavelo sabía que su análisis no era tan completo como para que un desconocido como él que, además, no tenía dinero ni fama, pudiera hacer semejante labor. El que él entienda claramente el papel de los ejércitos muestra implícitamente la hipótesis de la presente investigación, con respecto a esta última aseveración.

Dentro de los elementos que se encuentran en este autor y que lo vinculan con la ética están los siguientes.

\section{La ética y Maquiavelo}

Primero, es claro que en sus escritos muestra un gran amor a la familia Medici, en especial a Lorenzo, lo cual muestra que quiere la unión de Italia a través del trabajo de este gran político. Lo anterior, desde su pensamiento amoral no es comprensible, pues la virtud del príncipe es lo que debe 
prevalecer, por lo cual ese amor no se explica, excepto desde una posición distinta a sus teorías. Entonces, existe en Maquiavelo un fundamento ético que surge de su amor y devoción a sus empleadores, por los cuales había tenido acceso a todos los elementos que luego van a conformar su pensamiento.

El segundo elemento, que también muestra la eticidad de este personaje, es la búsqueda de la unidad italiana, esto por cuanto en muchos de los escritos hace alusión a la triste realidad de una Italia desunida, que tienen como elementos la gran tradición romana, la cultura y el amor a la Patria. En este sentido, no es gratuito que desee que sean los italianos los que unifiquen a Italia, y no se convierta en parte de otro Estado, que desde su pensamiento, no es entendible, por lo cual, se vuelve a encontrar en la situación de su tiempo el otro elemento ético, de amor a la patria, a la cultura románica, que en el fondo traiciona y re direcciona su pensamiento hacia lugares que en su teoría no debería hacerlo.

El tercer elemento que lo vincula con la ética es el amor a su pueblo, para que este tenga una mejor calidad de vida. Maquiavelo por sus observaciones, se había dado cuenta que un Estado Nacional posee un mayor volumen de comercio, dinero y poder, que redunda en una mejor capacidad de sus ciudadanos de disfrutar de bienes y servicios, por lo cual, luchando por la 
unificación de su país, logra como efecto necesario una mejor posición económica y de vida para sus conciudadanos. Lo anterior no se explica, pues el príncipe no debe buscar el bien de sus gobernados, sino el suyo propio.

En conclusión, se cree que en un análisis concienzudo de nuestro autor, se puede claramente afirmar: Maquiavelo no es ni un amoral, ni desliga tan radicalmente la política con la moral, pues, al interior de su ser, sus valores como italiano y heredero de la cultura greco-romana, no lo sustraen de un análisis ético de sus posiciones teóricas. 
Aristóteles. (2010). La Política. Madrid: Editorial Mestas ediciones.

Agustín de Hipona. (1988). La Ciudad de Dios. Madrid: Biblioteca de Autores Cristianos

Bois, Guy. (1991). La Revolución del año mil. Barcelona: Editorial Crítica.

Burke, Peter. (2000). El Renacimiento en Europa. Barcelona: Editorial Crítica.

Forte, Juan. (2011) Maquiavelo el arte del Estado. Madrid: Editorial Gredos.

Giglioli Geovanna. (1990). La Revolución teórica del Príncipe de

Maquiavelo. En Revista de Filosofía de la Universidad de Costa Rica,

Vol. 28, números 67-68, San José: Editorial UCR.

Maquiavelo. (2011). El Príncipe. Madrid: Editorial Gredos (2011). Discursos Sobre la Primera Década de Tito Libio.

Madrid: Editorial Gredos. . (2011). El Arte de la Guerra. Madrid: Editorial Gredos.

Platón. (2008). La República. Madrid: Editorial Nueva Acrópolis.

Rousseau, Jean Jacques. (1996). El Contrato Social. San José: Editorial Educa.
Referencias bibliográficas 
Nicolás Maquiavelo un amoral...

Santo Tomás de Aquino. (1988). Suma Contra los gentiles. Madrid:

Biblioteca de Autores Cristianos. (2001). Comentarios a libros de Aristóteles.

Pamplona: Editorial EUNSA.

Ullmann, Walter. (1965). La Historia del pensamiento político en la Edad

Media. Madrid: Editorial Ariel. 